\title{
Screening for ischaemic heart disease risk factors at a health fair: low attendance by those at highest risk
}

\author{
M WATTS ${ }^{1 *}$ AND I S JOHNSON ${ }^{2} \dagger$ \\ From ${ }^{1}$ Sheffield Health Authority and ${ }^{2}$ Trent Regional Health Authority.
}

ABSTRACT Among people attending a heart disease screening project at a Health Fair in Sheffield, only 22 of $425(5 \cdot 2 \%)$ lived in areas with more than $25 \%$ of the population belonging to social classes IV or V. The incidence of heart disease is known to be particularly high in these areas, where $15 \cdot 1 \%$ of the total population live. By analysis of the attendance rates from districts other than those immediately adjacent to the site of the Health Fair, we found that the strength of this inverse correlation increased, suggesting that the problems of access are probably greater for people living in deprived areas than for others.

Despite the fact that multiple risk factor intervention applied on a mass basis during adult life has not yet been shown convincingly to be of benefit in preventing ischaemic heart disease, ${ }^{1-4}$ many still argue that strategies aimed at changing the health related behaviour of the community as a whole are the best approach to reducing the incidence of this condition. $^{5-9}$ A mass screening initiative for ischaemic heart disease was undertaken at the Sheffield Health Fair in June 1985.

This Fair was arranged to coincide with the Health Education Council's 2000 mile "Great British Fun Run" which, together with locally organised events (such as the Sheffield Health Fair), aimed to raise public awareness of the value of health and exercise.

In Sheffield the Fair was coordinated by the Health Education Unit with financial backing of $£ 10000$ from the District Health Authority. A variety of activities were organised including cooking for a healthy diet, fitness testing and exercise instruction, gymnastic displays and information on local self help and community groups such as "Drug Line". Opportunities for cervical cancer and ischaemic heart disease risk factor screening were provided by Health Authority staff. Analysis of the characteristics of people who took advantage of this opportunity to be screened for heart disease risk factors is the basis for this paper.

* Present address and address for correspondence: Communicable Diseases (Scotland) Unit, Ruchill Hospital, Bilsland Drive, Glasgow G20 9N.

† Present address: Leicestershire Hospice, Groby Road, Leicester LE3 9QE.

\section{Methods}

Screening for ischaemic heart disease risk factors was conducted in two adjacent marquees by volunteers recruited from Health Authority staff. In the first marquee, height and weight were checked by a nurse and a questionnaire about health related behaviour completed. In the second, blood pressure was measured by a doctor and, after noting the responses on the questionnaire, appropriate advice was given or action taken. Details were recorded on a printed form, a copy of which was sent to the person's general practitioner. The Fair was publicised in the local newspaper and on the local radio. Posters were placed on the perimeter fence of the venue. The population and social class composition of Sheffield postal districts were obtained from the 1981 OPCS census ${ }^{10}$ and mortality data for ischaemic heart disease from 1985 OPCS death tapes. ${ }^{11}$ Here we record the results of an analysis of the area of residence of those people attending for screening with respect to the social class composition and known incidence of ischaemic heart disease in these areas, and the relationship of the distance from the site of the Health Fair.

\section{Results}

Five hundred and forty people participated in ischaemic heart disease risk factor screening over a two and a half day period. Of these, people under the age of 16 years, those living outside the Sheffield city boundary and those whose postcode was not noted were excluded, leaving $\mathbf{4 2 5}$ for analysis. 
Attendance rates of the adult population were calculated by postal sector (table 1) and grouped into quintiles as shown in the figure. As expected, there was

Table 1 Health fair attendance rates by postal sector

\begin{tabular}{|c|c|c|}
\hline $\begin{array}{l}\text { Postal } \\
\text { sector }\end{array}$ & $\begin{array}{l}\text { Number attending } \\
\text { ( } 95 \% \text { confidence } \\
\text { intervals) }\end{array}$ & $\begin{array}{l}\text { Attendance rate per } \\
1000 \text { resident adult } \\
\text { population }\end{array}$ \\
\hline S1 & $1(0-3)$ & 1.03 \\
\hline S2 & $11(5-18)$ & 0.28 \\
\hline S3 & $4(0-8)$ & 0.79 \\
\hline S4 & $2(1-3)$ & 0.19 \\
\hline S5 & $14(7-21)$ & 0.25 \\
\hline S6 & $43 \quad(36-50)$ & 0.80 \\
\hline S7 & $25 \quad(15-35)$ & $2 \cdot 15$ \\
\hline S8 & $35 \quad(23-47)$ & 0.77 \\
\hline S9 & $5(1-9)$ & 0.26 \\
\hline S10 & $36 \quad(24-48)$ & $2 \cdot 34$ \\
\hline S11 & $139(116-162)$ & $4 \cdot 24$ \\
\hline S12 & $19(11-28)$ & 0.53 \\
\hline S13 & $22(13-31)$ & 0.89 \\
\hline S14 & $6(1-11)$ & 0.64 \\
\hline S17 & $18 \quad(10-26)$ & 1.40 \\
\hline S19 & $7(2-12)$ & 0.51 \\
\hline S30 & $38 \quad(26-50)$ & 0.90 \\
\hline
\end{tabular}

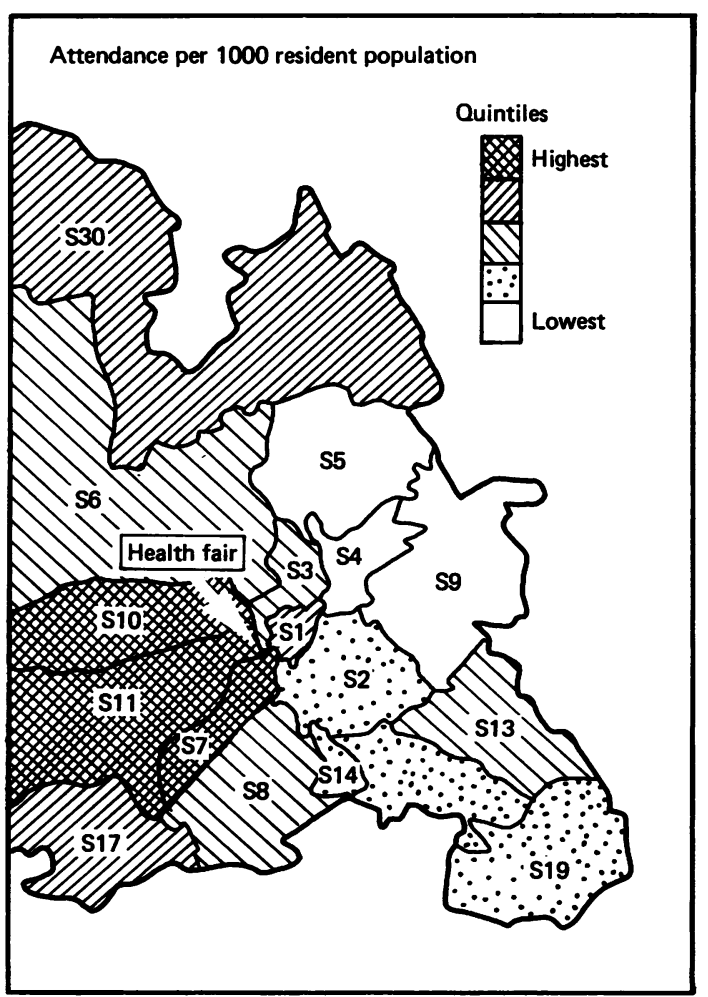

Figure Attendance rates at Health Fair in residents of surrounding postal districts, grouped by quintiles. a tendency for the highest rates to be found in the districts nearest to the site of the Health Fair. More importantly, comparison of the attendance rates with the percentage of people belonging to social class IV or $\mathrm{V}$ in that postal sector showed there to be a significant inverse correlation $\left(r_{s}=-0.6021, p<0.05, d F=16,2\right.$ tail), with the lowest attendance rates being found in the most deprived areas. When those districts immediately adjacent to the site of the Health Fair were excluded (ie, those with boundaries meeting that of "S11"), the negative correlation between social class and attendance rate became much stronger $\left(r_{s}=-0.8226, p<0.01, d F=12,2\right.$ tail $)$.

As shown in table 2 , there was a significant correlation between death rates from IHD in the 25-64

Table 2 Mortality from ischaemic heart disease and social class by postal sector

\begin{tabular}{llc}
\hline $\begin{array}{l}\text { Postal } \\
\text { sector }\end{array}$ & $\begin{array}{l}\text { Mortality rate from IHD } \\
\text { per } 1000 \text { adults }\end{array} 25-64$ years & $\begin{array}{c}\% \text { Social class } \\
\text { IV and } V\end{array}$ \\
\hline S1 & 3.62 & $30 \cdot 1$ \\
S2 & 1.99 & $26 \cdot 4$ \\
S3 & $2 \cdot 40$ & $27 \cdot 1$ \\
S4 & 1.00 & $22 \cdot 6$ \\
S5 & $2 \cdot 26$ & $24 \cdot 0$ \\
S6 & $2 \cdot 21$ & $17 \cdot 3$ \\
S7 & $2 \cdot 33$ & $12 \cdot 0$ \\
S8 & 1.54 & $16 \cdot 2$ \\
S9 & 1.45 & $20 \cdot 4$ \\
S10 & 0.81 & $9 \cdot 30$ \\
S11 & 0.73 & $8 \cdot 90$ \\
S12 & $2 \cdot 32$ & $18 \cdot 1$ \\
S13 & 1.92 & $18 \cdot 3$ \\
S14 & 2.99 & $26 \cdot 2$ \\
S17 & $1 \cdot 35$ & $5 \cdot 10$ \\
S19 & $2 \cdot 15$ & $18 \cdot 1$ \\
S30 & 1.76 & $14 \cdot 1$ \\
\hline
\end{tabular}

IHD $=$ ischaemic heart disease

years age group, and the percentage of social class IV or $\mathrm{V}$ in these districts $\left(r_{s}=0.6119, p<0.05, d F=16,2\right.$ tail), thus confirming the well known relationship between these variables.

\section{Discussion}

Opportunistic screening on a mass basis at a Health Fair is just one of the many possible ways of screening for ischaemic heart disease risk factors. In Sheffield the direct costs of the project were minimised by the use of volunteers, and the Health Fair offered health education benefits beyond the screening exercise. Nevertheless, the opportunity costs of such a venture are not inconsiderable and it is worth conjecturing whether the money invested by the District Health Authority was well spent, especially since other health education projects have been shown to receive most 
attention from those who least need it. ${ }^{12}$ In our study, only $87(16 \%)$ of participants admitted smoking tobacco in some form, and $314(58 \%)$ claimed to exercise briskly at least three times a week. Other studies have shown that about a third of the general population smoke and less than one fifth take regular brisk exercise. ${ }^{213-15}$

Our study has shown that, in Sheffield, those people living in areas where the incidence of death from IHD is highest are less likely to participate in risk factor screening than those living in areas of lower incidence (who by implication are at lower risk).

We have also shown that when the analysis is confined to the residents of postal districts which are not immediately adjacent to that in which the event was held, there is an increase in the negative correlation between low social class and attendance rate. One possible explanation for this finding might be, as suggested by Wrench and Irvine, ${ }^{16}$ that access to the venue is a more important barrier to people of social classes IV and V than to others. In 1985 Sheffield had a highly subsidised public transport system with frequent buses charging a maximum fare of 20 pence. Thus if access is a major factor, then this will be a far more potent deterrent in most other areas with less favourable transport policies.

Part of the different attendance rates may have been due to unequal advertising coverage with city wide newspaper and radio announcements reaching a more selected audience than in the area of the event, where the message was reinforced by posters.

We conclude that the site of such events may be an important factor in determining their effectiveness. However, it could be argued that Health Fairs of this type are inherently less attractive to the people of social classes IV and V irrespective of the distance from the venue. As such they would yield a poor return on investment of scarce health promotion funds. Our findings would be equally consistent with such a view.

\section{References}

${ }^{1}$ Oliver MF. Targetting coronary risk factor control. Lancet 1981; ii: 449-50.

2 Multiple Risk Factor Intervention Trial Research Group. Multiple Risk Factor Intervention Trial: risk factor changes and mortality results. $J A M A$ 1982; 248: 1465-77.

${ }^{3}$ Oliver MF. Does control of risk factors prevent coronary heart disease? $\mathrm{Br} \mathrm{Med} J$ 1982; 285: 1065-6.

4 The South East London Screening Group. A controlled trial of multiphasic screening in middle age: results of the South East London Screening Study. Int J Epidemiol 1977; 6: 357-63.

${ }^{5}$ World Health Organisation. Prevention of coronary heart disease. Report of a WHO Expert Committee. WHO Technical Report Series 678. Geneva: WHO, 1982.

${ }^{6}$ Rose G. Strategy of prevention: lessons from cardiovascular disease. Br Med J 1981; 282: 1847-51.

7 The Royal College of General Practitioners. Prevention of arterial disease in general practice. Report from General Practice no. 18. London, 1981.

${ }^{8}$ Puska P. The North Karelia Project: an attempt at community prevention of cardiovascular disease. $W H O$ Chron 1973; 27: 55-8.

${ }^{9}$ Parish R, Catford J, Nutbeam D. Breathing life into Wales: progress in the Welsh Heart Programme. Health Trends 1987; 19: 23-7.

${ }^{10}$ Office of Population Censuses and Surveys. 1981 census, small area statistics. London: HMSO.

11 Office of Population Censuses and Surveys. Death tapes for RHAs 1985. Titchfield, Hampshire: OPCS.

12 Williams BT. Are public health education campaigns worthwhile? Br Med J 1984; 288: 170-1.

13 Campbell MJ, Browne D, Waters WE. Can general $\sigma \mathcal{C}$ practitioners influence exercise habits? Br Med J 1985; 290: $1044-6$.

${ }^{14}$ Office of Population Censuses and Surveys. General Household Survey 1984. London: HMSO.

15 Morris JN, Everett MG, Pollard R, Chave SPW. Vigorous exercise in leisure-time: protection against heart disease. Lancet 1980; ii: 1207-10.

16 Wrench JG, Irvine R. Coronary heart disease: account of a preventive clinic in general practice. $J \boldsymbol{R}$ Coll Gen Pract 1984; 34: 477-81. 